\title{
Consciência metatextual, compreensão leitora e resumo de histórias - possíveis relações em uma perspectiva psicolinguística
}

\author{
Metatextual Awareness, reading comprehension and story summary-possible \\ relations in a psycholinguistic perspective
}

\section{Marília Marques Lopes}

Universidade Federal do Rio Grande do Sul - UFRGS - Porto Alegre - Rio Grande do Sul - Brasil

Resumo: A criança, antes mesmo do início do ensino formal, tem longo percurso no desenvolvimento de capacidades de leitura e de escrita, as quais se referem tanto à compreensão leitora como à consciência do material escrito, qualquer que seja ele. Essa Consciência Metatextual, segundo Jean-Émile Gombert (1992), é composta de coerência, coesão e de estrutura textual, sendo fator que pode contribuir para um desempenho satisfatório na compreensão de textos, bem como na escrita de resumos. A tese que originou este artigo utilizou como referencial teórico os estudos desse autor sobre consciência metatextual. Tratou especificamente das correlações entre consciência metatextual, compreensão leitora e elaboração de resumos de narrativa por estudantes de $5^{\circ}$ e 6ํㅜ anos do Ensino Fundamental de três escolas públicas de Porto Alegre. Para avaliar essa correlação, realizamos testes de escolha simples para verificar a Consciência Metatextual $(C M)$ e a Compreensão Leitora (CL), e de Resumo de narrativa $(R)$, avaliado através de um quadro de referência contemplando as categorias de eventos principais, autonomia e estrutura narrativa. Os resultados desses três aspectos relacionados entre si foram confrontados de maneira a se verificar em que medida essas correlações ocorreram. Constatou-se que, para um sujeito resumir uma história, a competência que parece mais presente é sua habilidade metatextual, ou seja, sua atenção para a superestrutura do texto-fonte. Ao mesmo tempo, essa consciência metatextual também é importante para a compreensão do texto, na medida em que se constitui numa espécie de moldura que o orienta na compreensão de uma história.

Palavras-chave: Resumo. Consciência metatextual. Compreensão leitora.

Abstract: Even before formal education, children have a long term for developing their abilities of reading and writing, and these abilities relate to both reading comprehension and awareness of texts, whatever they are. This Metatextual Awareness, according to Jean-Émile Gombert (1992), comprises coherence, cohesion and text structure, and is a factor that can determine a good comprehension, as well as summary writing. The thesis this article is about employed Gombert's theoretical framework on that subject, and dealt with correlations among metatextual awareness, reading comprehension and summary writing of narratives by 5th and 6th grade students in three public schools in Porto Alegre. To check these correlations, we applied simple choice tests to evaluate metatextual awareness and reading comprehension, and also a test of summary writing through a reference framework comprising categories like main events, writing autonomy and narrative structure. The results of these three aspects were related and we found that for summarizing a story the most important is the subject's metatextual ability, or his attention to source text. At the same time, this metatextual awareness is also relevant to text comprehension as it is a kind of frame that guides him in understanding a story.

Keywords: Summary. Metatextual awareness. Reading comprehension. 


\section{Introdução}

O convívio com crianças em idade escolar faz suscitarem alguns questionamentos sobre como se encaminha o seu aprendizado nas séries iniciais, e sobre como acontece a constituição do seu conhecimento e seu progresso em direção à construção de sua autonomia linguística e cognitiva. Em sentido amplo, no ambiente escolar a criança progride em sua capacidade de criar e controlar seus próprios mecanismos de aprendizado através da leitura, a qual vem a se tornar um fator fundamental e facilitador no desempenho de suas atividades intelectuais futuras. Mas a construção desse aprendizado se inicia nos primeiros anos de vida, no ambiente doméstico informal e em meio aos diálogos que ela estabelece com os adultos com quem convive.

O psicólogo da área do ensino Jean-Émile Gombert (2003) afirma existir precocemente, na criança, uma sensibilidade para o aprendizado da língua que faz parte de processos não controlados de modo consciente pelo indivíduo, e que emergem nos dois primeiros anos de vida da criança, acompanhando-a na fase adulta. Pesquisadores locais como Alina Galvão Spinillo também admitem a existência de uma precoce capacidade de reflexão sobre a língua, em especial o texto, que pode se manifestar no estranhamento em relação à máformação de frases, por exemplo. Segundo a autora, desde os cinco anos de idade a criança já tem uma ideia sobre textos de gêneros distintos (SPINILLO; SIMÕES, 2003) e que, com o passar do tempo e das experiências vividas em sala de aula, ela desenvolve certo distanciamento dos textos e passa a analisá-los e julgá-los corretamente, tanto em seu conteúdo e funções como em suas mais diversas formas de apresentação. Gombert (2013) menciona as aprendizagens implícitas, que "se apoiam em capacidades funcionais antes dos primeiros contatos com a escrita" (p.117). Assim, sem perceber, a criança antes da escola adquire os primeiros conhecimentos sobre a escrita, associando aspectos morfológicos, fonológicos e grafológicos. Como diz Gombert (2013), a frequência da exposição e a manipulação da criança em relação às formas de escrita impulsionam as aprendizagens implícitas. Estas prosseguem conforme são praticadas regularmente atividades de leitura e escrita. É através dessa aprendizagem que surgem as capacidades epilinguísticas e, posteriormente, as capacidades metalinguísticas, embora aquelas continuem a evoluir através da manipulação e repetição da escrita quando as pessoas leem ou escrevem (idem, p.121). Assim, é esperado que essas capacidades de ir além do texto sejam importantes em qualquer situação de leitura, e sejam quase que automatizadas à medida que exercitadas na escola, em especial.

Este artigo procura relatar os percursos de uma Tese de Doutorado defendida em janeiro de 2015. A princípio, o Resumo foi minha única preocupação, tendo este sido também tratado durante o Mestrado, concluído há alguns anos. Em conjunto com a orientadora, percebi que ele precisava ter seu status reforçado - ou não - em relação a outras formas de se avaliar a leitura, levando-se em conta aspectos macro ou microlinguísticos. Foi assim que agregamos a Consciência Metatextual e a Compreensão Leitora, que foram correlacionadas com a escrita de Resumo de histórias. Embora o resumo seja também considerado um meio de se avaliar a compreensão do leitor, ele diferencia-se por ser uma produção escrita e por exigir a soma de habilidades de reflexão, síntese e escrita que se presume estejam presentes entre alunos de $5^{\circ}$ e $6^{\circ}$ anos do ensino fundamental, sujeitos das pesquisas realizadas. Nessa fase escolar, em que os alunos presumivelmente já desenvolveram potencialidades com relação à leitura e à escrita, e que se apresenta como limítrofe entre os níveis fundamental I e II, é interessante avaliar o que eles atingiram em termos de desenvolvimento e traquejo com relação a textos escritos e sua compreensão tanto em nível de forma como de conteúdo. Tendo isso em mente, somado às horas-aula do Curso e às sempre edificantes discussões entre colegas, partiu-se para reflexões acerca das relações leitura-compreensão estabelecidas por crianças na metade do ensino fundamental. A tese em questão tratou de relacionar três tipos de avaliação da leitura, unindo instrumentos 
como testes de escolha simples e escrita de resumo de uma narrativa.

\section{Breve contexto teórico}

Durante a leitura, mesmo sem saber o leitor lança mão de estratégias para compreender o que lê, e isso é consequência das vivências escolares. Isabel Solé (1998) define estratégias como procedimentos de caráter elevado, ou seja, de nível superior, que envolvem planejamento, avaliação e mudança possível nos rumos de qualquer atividade. Considerando procedimento como conteúdo de ensino, a autora refere que estratégias devem ser ensinadas, uma vez que estas não surgem, amadurecem ou se desenvolvem de forma gratuita ou natural no indivíduo. Elas podem ser executadas através de reflexões e tentativas, mas isso não significa que não possam ser ensinadas. Estratégias são, portanto, procedimentos que envolvem 0 cognitivo e o metacognitivo.

As estratégias regulam 0 processo de compreensão, uma vez que atuam na seleção, avaliação, manutenção ou abandono de hipóteses pelo leitor a respeito do conteúdo do que lê (ALVES, 2010, p. 19). São importantes também porque orientam atitudes do leitor durante essa atividade. Para van Dijk e Kintsch (1983), elas

são parte do nosso conhecimento geral; representam o conhecimento procedimental que temos sobre o entendimento do discurso. São configurações abertas. Precisam ser aprendidas cada vez mais até serem automatizadas. Novos tipos de discurso e novas formas de comunicação podem exigir o desenvolvimento de estratégias. Enquanto algumas delas, como a compreensão de palavras e orações, são adquiridas relativamente cedo, outras, como a inferência da essência, são adquiridas mais tarde.

A leitura, dada sua complexidade, pressupõe a presença de inúmeros subprocessos que, conforme Leffa (1996), se "encadeiam de modo a estabelecer canais de comunicação por onde, em via dupla, passam inúmeras informações entre leitor e texto" (p.24). Torna-se, então, tarefa difícil delimitar até onde vão e a partir de onde surgem esses subprocessos, ou cada um deles. Enfim, a utilização de estratégias em leitura, muitas vezes individuais a cada leitor e sendo ou não automatizadas, leva-o a um nível de proficiência desejável por envolver um distanciamento do objeto em questão - o texto - proporcionando um olhar mais crítico e consciente sobre ele. O leitor se engaja na construção de significado, na identificação da micro, macro e superestrutura do texto e estabelece relações entre os enunciados e entre estes e o que já conhece relativamente ao tópico tratado. Como se percebe, ele mobiliza muito de suas capacidades cognitivas com um único objetivo, a compreensão que nos parece coroar uma série de processos mentais.

É relevante a distinção entre estratégia de leitura - predominantemente intencional - e processamento da leitura - que acontece de forma não deliberada na mente do leitor. A literatura psicolinguística propõe três modelos cognitivos de processamento da leitura: ascendente, descendente e interativo. Segundo Sternberg (2010), as abordagens ascendente e descendente aplicam-se a praticamente todos os aspectos da cognição, e no trabalho relatado aqui, a leitura, de certa forma, delas se apropria para tentar explicitar formas de se ler.

O leitor principiante não conta com o reconhecimento visual instantâneo de palavras, mas realiza operações de análise e síntese para identificálas. O significado é então apreendido após a decodificação em palavras auditivamente familiares (KATO, 1999, p. 34). Essas operações, inicialmente realizadas com letras, estendem-se também a sílabas e a partes maiores das palavras. A leitura inicial acontece de forma hierárquica, das unidades mínimas da palavra às frases, parágrafos e ao texto como um todo, quando o leitor já conta com um repertório linguístico mais robusto. Parte-se, portanto, do processamento ascendente, relacionado à decodificação, e segue-se rumo ao processamento descendente, o qual pressupõe uma decodificação bem-sucedida e faz uso intenso do conhecimento prévio do leitor, que privilegia a construção da macroestrutura do texto. Esses conceitos são importantes, pois compreendem dois tipos iniciais de 
relação do leitor com o texto, e que, com o passar do tempo e com o acúmulo de experiências leitoras e vivências do leitor, tornam-se automatizadas. Quando esses dois processamentos colaboram entre si, temos o processamento interativo.

O processamento interativo na leitura é defendido, por exemplo, por Solé (1998) e Colomer e Camps (2002). Ele abrange o ascendente e o descendente, que atuam um sobre o outro. Cada palavra, letra, frase gera expectativas no leitor, de modo progressivo. Ao mesmo tempo, dadas as expectativas em nível semântico do texto, estas geram uma busca de verificação em nível inferior, ou seja, léxico, sintático etc. É um movimento de dentro para fora e de fora para dentro do texto, já que fazemos, ao ler, inúmeras relações tanto entre as palavras no texto como entre elas e o que conhecemos previamente (conhecimento prévio linguístico e de mundo). A memória, tratada com maior detalhe na tese, faz as devidas "costuras" para gerar a compreensão, proporcionando que o leitor faça inferências e predições necessárias à leitura.

O processamento descendente possibilita a mobilização dos esquemas, ou conjuntos de conhecimento de mundo. Segundo Kato (1999), o leitor descendente é construtor de significado, enquanto que o leitor ascendente exerce um papel de analisador, pois se atém a palavras e frases para formar sua compreensão. A autora acrescenta que a leitura descendente é possível quando há a presença de uma palavra no léxico mental do leitor; esse processamento acontece com base no modelo situacional de compreensão, envolvendo o contexto, já que conta com o conhecimento extralinguístico do leitor. Tem sido preferencialmente abordado pela psicologia cognitiva. Já o processamento ascendente ocorre quando o leitor se depara com informações que pouco ou nada conhece, porque ocorre com base no próprio texto, sendo dependente dele. Kato (idem) também defende uma alternância entre os processos descendente e ascendente em leitura, ou seja, é desejável que haja interação entre o texto e o leitor em meio à leitura. Sendo assim, os dois tipos de processamento em leitura têm aspectos importantes para o leitor, já que podem ser vistos como complementares, caracterizando o leitor proficiente que, em suma, adota uma atitude metacognitiva frente à leitura - sabe avaliar como e quando necessita adotar uma ou outra postura frente ao texto. Os processamentos em leitura são elementares, e atuam dentro de modelos de compreensão leitora.

A Psicolinguística propõe modelos de compreensão leitora, os quais procuram descrever como o leitor lida com a informação verbal por meio da escrita ou da audição de textos diversos. Van Dijk e Kintsch (1983) apresentaram um modelo de compreensão leitora que foi adotado na tese, pois trata, entre suas propostas, do Resumo como parte importante dos processos de compreensão leitora. Em seu modelo de compreensão, a ênfase é no leitor em seu processo construtivo da própria compreensão. $O$ psicólogo Walter Kintsch e o linguista van Dijk propuseram um modelo de compreensão que leva em conta as limitações da memória de curto prazo do indivíduo: o processamento de um texto é realizado em ciclos (correspondendo a uma frase) até ser formado um conteúdo com as informações mais importantes, ou uma estrutura geral de significado. Estas informações relevantes, chamadas proposições, compõem a macroestrutura do texto, que permanece na memória episódica juntamente com os itens mais recentes do ciclo, até o ciclo seguinte, o qual irá alterar essas representações anteriores na memória episódica. Van Dijk afirma que o cenário de uma narrativa, por exemplo, é definido em um macronível de análise, e não em termos de frases individuais. Gradativamente, portanto, um texto-base é construído, e para isso o leitor conta com seu conhecimento prévio. Esse textobase constitui-se pelo conhecimento do leitor acerca da própria linguagem e do mundo e envolve inúmeras inferências de modo a engendrar a coerência semântica entre as proposições, ou informações relevantes. A representação que o leitor constrói é a todo momento cotejada com o que ele já sabe sobre contextos similares, e é importante para delimitar o papel do texto-base: este deve ater-se somente ao que está escrito no texto. 
Para van Dijk e Kintsch (1983), os objetos linguísticos são vistos em termos de níveis separados - sintaxe, semântica, morfologia, pragmática. Porém, do ponto de vista dos modelos de processamento, esses níveis não são tão relevantes, pois as informações durante a leitura interagem de maneira bastante complexa. Isto faz com que a interpretação semântica não se oriente pela análise sintática, mas ocorra até mesmo tendo como base uma estrutura de superfície incompleta, e a análise sintática se dê com o auxílio de informações pragmáticas ou sintáticas (idem, p. 10). O modelo de Van Dijk e Kintsch opera em blocos mais complexos do que unidades sintáticas ou semânticas, sempre integrando informações de níveis diversos. Segundo os autores, vamos da compreensão de palavras à compreensão de frases onde essas palavras têm várias funções, e assim a frases complexas, por exemplo. Mesmo assim, ocorre um feedback entre unidades menos e mais complexas: compreender a função das palavras em uma frase dependerá da estrutura funcional desta como um todo, nos níveis sintático e semântico. Ou seja, em vez de operar um modelo de processamento estrutural convencional, trabalhamos com um modelo estratégico.

Esse modelo de compreensão leitora envolve grandes quantidades de conhecimento, tanto episódico como aquele contido na memória semântica, formada pelo nosso conhecimento adquirido verbal e de mundo, mais abstrato. Tem como proposta descrever a estrutura semântica do discurso, que é construída com base em níveis de representação do texto, ou discurso, em sentido amplo, quais sejam: microestrutura, macroestrutura e superestrutura. $O$ nível microestrutural diz respeito à organização sequencial e coerência local do discurso; são as representações semânticas que o sujeito elabora com base nas frases ou conjunto de sentenças. Nesse nível utilizam-se estratégias de coerência local de modo a se verificar ligações relevantes entre sentenças, tendo como foco aspectos coesivos. O nível macroestrutural se refere à coerência global do discurso, às relações explícitas ou não das proposições, que constituem o tema em questão. Nele o leitor lança mão de estratégias de coerência global, fazendo uso de inferências para criar as macroproposições.

O leitor, assim, faz uso de estratégias de forma interativa (e podemos incluir aqui a integração dos processamentos ascendente e descendente), utilizando níveis de informação linguístico, contextual e cognitivo. Esses níveis dizem respeito, respectivamente, a aspectos morfológicos, fonológicos, sintáticos etc.; a aspectos pragmáticos ou situacionais; a aspectos de conhecimentos gerais, episódicos ou textuais. As hipóteses que ele formula, respaldadas por esses níveis de informação, poderão ser, portanto, confirmadas ou não, ou mesmo retomadas enquanto o indivíduo lê. Forma-se então uma possível representação semântica na sua mente, na forma de proposições, denominada texto-base pelos autores e definidas em termos de proposições e relações entre elas. O texto-base representa 0 significado do texto do modo como ele é apresentado ao leitor, sendo que esse conteúdo é utilizado na construção do modelo situacional, ou modelo mental do que o texto apresenta. Em suma, esse modelo mental une o que está escrito mais o que o leitor traz de informações prévias como subsídio para a compreensão. Segundo van Dijk (1983),

O principal aspecto do modelo em questão é de que a compreensão do discurso envolve não somente a representação desse textobase na memória episódica, mas ao mesmo tempo reúne a ativação, atualização e outros usos do modelo de situação na memória episódica: é a representação cognitiva de eventos, ações, personagens, enfim, a situação como um todo de que trata o texto. ( $p$. 11-12)

Ao ativar seus conhecimentos prévios durante a leitura, ação que parece involuntária, o leitor põe à prova sua consciência sobre a própria língua, que já vem sendo constituída desde quando ele articula as primeiras palavras. Essa consciência metalinguística foi proposta por Tunmer e Herriman (1984), podendo existir em diversos níveis: fonológica, morfológica, lexical, sintática e pragmática. Constitui-se desde os primeiros anos de vida e continua a se especializar, tornando a compreensão cada vez mais aprimorada. 
Na relação do leitor com o texto, há um conjunto de operações metatextuais envolvidas no controle intencional, tanto na compreensão como na produção, do ordenamento de enunciados em unidades linguísticas maiores. Para a análise mais específica desses comportamentos, Gombert (1992) propõe a Consciência Metatextual, que é um conjunto de "operações metatextuais envolvidas no controle intencional, tanto na compreensão como na produção, do ordenamento de enunciados em unidades linguísticas maiores" (p.121, tradução desta autora). Pesquisas indicam que a atividade metatextual relaciona-se a esses comportamentos de controle do processamento textual com vistas às características intrínsecas do texto e também às suas características extralinguísticas. Segundo o autor, esse fato torna difícil e até mesmo artificial separar o que é de natureza metalinguística do que não é, embora seja de âmbito metacognitivo (p. 149).

A Consciência Metatextual proposta por Gombert tem como foco a estrutura e organização textual de gêneros distintos, ou seja, a análise do texto através de um monitoramento intencional. Divide-se, segundo esse autor, em Coerência, Coesão e Estrutura textual, destacando especialmente dentro da coesão as inferências, compatibilidade de informação nova com o conhecimento prévio e a compatibilidade entre as diferentes ideias presentes no próprio texto. Essa consciência é válida não somente para quem escreve textos, mas para quem lê - o planejamento do que escrever, bem como a predisposição do leitor podem ser determinantes nas respectivas tarefas. Por trás dessas atividades, há um conjunto de comportamentos que controlam o processamento do texto, quer em sentido formal como no sentido das representações não estritamente linguísticas, como mencionado anteriormente, ou seja, o texto sendo visto como objeto de reflexão e como comunicação entre os indivíduos, respectivamente. Como menciona Spinillo,

Nas situações de comunicação, o foco de nossa atenção se volta para as ideias que desejamos comunicar e para o significado que precisamos atribuir. No entanto, se necessário, podemos voltar nossa atenção, de forma consciente e deliberada, para o texto em si mesmo: sua estrutura, suas partes constituintes, suas convenções linguísticas e marcadores (coesivos, pontuação). (2009, p.78)

Enfim, a Consciência Metatextual trata das relações intralinguísticas do texto. Gombert (1992), ao lançar essa proposta de Consciência Metatextual, privilegia o funcionamento do texto, ou seja, o leitor assume uma postura analítica frente a ele. Podemos acrescentar que, dado que este foi escrito com uma finalidade básica, que é a compreensão, nos parece que a estrutura e relações intrínsecas a ele estariam a serviço da própria compreensão.

A tese de que tratamos aqui se configurou assentada nessa previsível capacidade de o aluno ir além do texto, ou seja, de analisar uma história na sua totalidade - como ela se apresenta e o que ela veicula. As atividades propostas aos sujeitos que participaram do trabalho se enquadram no âmbito de pesquisas que requerem uma atitude de reflexão sobre o texto, e que podem voltar-se para aspectos microlinguísticos (coesão, pontuação, por exemplo) ou para aspectos macrolinguísticos (estrutura e conteúdo), remetendo a questões de gêneros textuais. Uniram-se, portanto, aspectos relativos à expressão e ao conteúdo de uma história, avaliados por meio de três testes distintos: Consciência Metatextual (CM), Compreensão Leitora $(\mathrm{CL})$ e Resumo $(\mathrm{R})$ de história, utilizando para tal uma narrativa como texto-fonte.

Os objetivos da pesquisa, estabelecidos de acordo com as hipóteses aventadas, foram verificar: a) a correlação entre a consciência metatextual (CM) e a produção de resumo $(R)$ de história; b) a correlação entre a compreensão leitora $(C L)$ e a produção de resumo (R) de história; c) a correlação entre a consciência metatextual (CM), a compreensão leitora $(C L)$ e a produção de resumo $(R)$. Anteriormente à coleta de dados propriamente dita, realizei uma testagem para avaliar e validar os instrumentos com oito participantes entre estudantes de graduação e de doutorado em Letras e professores universitários dessa mesma área. Essa verificação foi fundamental, pois nos possibilitou um feedback das atividades pretendidas para o teste-piloto. Posteriormente, apliquei testes-piloto entre alunos de uma turma do $5^{\circ}$ 
ano de escola estadual, dividida em três subgrupos, sendo que cada um deles recebeu os instrumentos para teste da CM, da CL e do R.

Elaborei três instrumentos, aplicados a 57 sujeitos de duas escolas públicas estaduais, respectivamente $5^{\circ}$ e $6^{\circ}$ ano; e uma vinculada a instituição federal de ensino, sendo estes sujeitos do $5^{\circ}$ ano. Os sujeitos tinham média de idade entre 11a $11 \mathrm{~m}$ e $12 \mathrm{a} 11 \mathrm{~m}$. Os testes utilizaram como base uma história de Gianni Rodari, intitulada "Uma volta pela cidade", e se constituíram de dez questões de escolha simples para avaliar a CM e para avaliar a CL; e um teste de resumo da história-fonte. Três encontros, entre agosto e setembro, foram realizados com cada turma para aplicar os instrumentos, da seguinte forma: no primeiro encontro, após a leitura de uma narrativa, os sujeitos fizeram resumo do texto; no segundo, após a leitura da mesma narrativa, os sujeitos realizaram o teste de compreensão leitora; e no último, realizaram o teste de consciência metatextual. A CM focalizou aspectos de coerência, coesão e estrutura textual, distribuídos entre os seguintes tipos de questões: 3 no âmbito da Coerência; 3 no âmbito da Coesão; e 4 que tratavam de Estrutura Textual, ou Superestrutura (no caso de uma narrativa, o esquema ternário: estado inicial, desenvolvimento-transformações, estado final). A CL teve como enfoque questões relacionadas ao entendimento dos eventos da história; o $\mathrm{R}$ focalizou aspectos de conteúdo e construção e ainda os elementos que indicavam início, desenvolvimento (transformações) e final da história. Cada um dos dois testes de escolha simples contou, ao final de cada uma das dez questões, com duas perguntas dissertativas de cunho metalinguístico: a) por que escolhi essa resposta; b) para chegar a essa resposta, pensei assim:..." Nos dias de aplicação dos testes objetivos, foram escolhidos $20 \%$ dos sujeitos em sala de aula para fazer o teste em local separado. Nessa ocasião, eles responderam por escrito às questões objetivas e oralmente às duas perguntas dissertativas após cada questão objetiva, o que foi gravado. Essas duas questões de caráter metacognitivo dispostas após cada questão nos testes de $\mathrm{CL}$ e CM foram classificadas em níveis I, II, III e IV, baseados em estudo de Spinillo (2003). Na tese propriamente dita, há quadros e tabelas registrando essas diretrizes e também os resultados atingidos.

De posse dos instrumentos de avaliação dos sujeitos, em consulta a um estatístico geramos inúmeros resultados, dos quais cumpre destacar aqui os mais gerais, e que se relacionam mais especificamente com o tema deste artigo: a correlação entre as principais variáveis da pesquisa, na Tabela 5. Para que pudesse situar melhor as amostras, elaborei questionários para caracterizá-las, os quais podem se vistos na versão integral da tese.

Tabela 5- Escolas A, B e C: médias dos escores nos testes de Resumo, Compreensão Leitora e Consciência Textual

\begin{tabular}{|c|c|c|c|}
\hline ESCOLA & Resumo & $\begin{array}{c}\text { Comp. } \\
\text { leitora }\end{array}$ & $\begin{array}{c}\text { Cons. } \\
\text { Metatextual }\end{array}$ \\
\hline A & 2,6 & 4,37 & 5,7 \\
\hline B & 5,1 & 5,17 & 6,6 \\
\hline C & 2,8 & 5,0 & 6,3 \\
\hline
\end{tabular}

Os melhores desempenhos deram-se no nível da Consciência Metatextual, para as três escolas. Como previsto, a escola B teve melhor desempenho do que as escolas A e C. A escola B é vinculada a instituição de ensino superior, e tem uma relação mais estreita com pesquisa. A escola A teve os piores desempenhos, o que pode se justificar por sua condição de maior vulnerabilidade, tanto no sentido das condições de ensino como no de situação dos próprios alunos. A escola $C$ foi intermediária; também apresenta problemas, ainda que menores, de condições de ensino e dos alunos. É precipitado afirmar de modo categórico prováveis causas para esses desempenhos e suas diferenças, mas dado o contexto educacional no país, essa é uma pequena amostra de como condições adversas podem impactar em resultados específicos como esses.

Para medirmos as correlações entre as variáveis dos testes de Resumo $(R)$, Compreensão Leitora (CL) e Consciência Metatextual (CM), foi utilizado o coeficiente de correlação linear de Pearson (r). Por serem mais abrangentes, adotamos na tese os 
critérios que Cohen (1988) ${ }^{1}$ propõe a respeito desses escores, que estabelecem valores entre 0,10 e 0,29 como pequenos; entre 0,30 e 0,49 como médios; e entre 0,50 e 1 como grandes. A Tabela 6 mostra essa correlação, incluindo as três escolas.

Tabela 6 - Escolas A, B e C: correlações gerais entre Compreensão Leitora, Consciência Metatextual e Resumo

\begin{tabular}{|c|c|c|c|}
\hline & Res & C. L. & C.M. \\
\hline Res & 1,00 & & \\
C. L. & 0,25 & 1,00 & \\
C.M. & 0,44 & 0,48 & 1,00 \\
\hline
\end{tabular}

A Tabela 6 revela as correlações investigadas. Nossa hipótese geral - de que haveria correlação entre os escores dos testes de Resumo, Compreensão Leitora e Consciência Metatextual entre sujeitos do $5^{0}$ e 6ำ ano do Ensino fundamental - foi confirmada no sentido de que houve, sim, uma correlação entre essas três variáveis. Analisando de modo mais detalhado, porém, surge a questão de o quanto essa correlação (segundo critério de Cohen) é importante e encaminharia para algumas conclusões. Isso nos remete às hipóteses específicas e aos objetivos da investigação:

- Objetivo "a" e Hipótese "a": cumprido esse Objetivo e testada essa Hipótese, verificamos que a CM e o R tiveram correlação de 0,44, e que há alguma correlação entre essas variáveis. A correlação é considerada moderada.

- Objetivo "b" e Hipótese "b": cumprido esse objetivo e testada essa Hipótese, verificamos que a CL e o R tiveram uma correlação de 0,25, e que a hipótese não foi corroborada, dado o índice fraco de correlação entre essas variáveis. Nossa explicação para este resultado reside no fato de que os dois testes avaliaram habilidades distintas, e a escrita, como produção mais sofisticada e que requer mais perícia, provavelmente interferiu nesse resultado.

- Objetivo "c" e Hipótese "c": cumprido esse Objetivo e testada essa Hipótese, verificamos que a CM e a CL tiveram o maior índice de correlação, 0,48.
Há maior correlação entre essas variáveis, significando que os sujeitos que tiveram bom desempenho no teste de CL também tendiam a ter bom desempenho no teste de CM. A correlação é moderada.

Atenção especial foi dada ao desempenho nos resumos. Elaborei uma estrutura da narrativa utilizada na análise dos resumos que contemplou o estado inicial, as transformações e o estado final, que fazem parte da construção do resumo, ou estrutura da história. As subcategorias em que essas produções foram avaliadas totalizaram cinco: Eventos principais (conteúdo); Autonomia (construção); Estrutura: Estado inicial, Transformações, Estado final (construção). Essas categorias estão no Quadro 5. Cada uma dessas subcategorias recebeu uma determinada pontuação, como mostra esse Quadro. Com o intuito de uniformizar os resultados, foi feita uma padronização desses pontos, uma vez que as escalas eram distintas. Feita essa padronização, os sujeitos que tiveram desempenho abaixo da média que foi estabelecida revelaram mais problemas na categoria Transformações, ou seja, nessa subcategoria se concentraram as maiores dificuldades dos Resumos escritos.

O Quadro 5 mostra o instrumento que foi criado para a análise dos resumos, que demandou a leitura preliminar de todas as produções para se chegar a um padrão do que foi escrito como resumo de narrativa pelos sujeitos. Assim, foi possível o julgamento de cada uma das produções escritas por mim e mais duas professoras, até se chegar a uma pontuação média. A pontuação total das categorias do Resumo, em princípio, totalizava 10. Porém, a Categoria Extensão, que equivalia a 2 pontos, foi retirada, uma vez que a consideramos inadequada. Passamos, assim, a considerar a contagem de palavras de cada produção escrita, o que no cômputo final acabou se revelando pouco relevante, como mostra a versão integral da Tese. Pode-se dizer que o instrumento do Quadro 5 foi o que mais demandou tempo e dedicação, haja vista a complexidade do material que tínhamos disponível, ou seja, os resumos dos sujeitos.

1 COHEN, Jacob. (1988). Statistical power analysis for the behavioral sciences. Hillsdale, NJ, Erlbaum. 


\begin{tabular}{|c|c|c|c|}
\hline $\begin{array}{l}\text { Categorias } \\
\text { do Resumo }\end{array}$ & $\begin{array}{l}\text { Sub- } \\
\text { categorias }\end{array}$ & Características da produção & Pontuação \\
\hline \multirow{4}{*}{$\begin{array}{l}\text { CONTEÚDO } \\
3 p\end{array}$} & \multirow{4}{*}{$\begin{array}{l}\text { Eventos } \\
\text { principais } \\
3 p\end{array}$} & $\begin{array}{l}\text { Ausentes. Predomínio de história/trechos distintos do texto-fonte. Erros de } \\
\text { compreensão. Cópia do texto-fonte. }\end{array}$ & 0,0 \\
\hline & & $\begin{array}{c}\text { Ausência de, ou poucos eventos principais. Alguns erros de compreensão. } \\
\text { Possíveis trechos distintos e cópia de trechos. }\end{array}$ & 1,0 \\
\hline & & $\begin{array}{l}\text { Eventos principais presentes, em sua maioria. Possíveis erros de } \\
\text { compreensão ou trechos distintos. Possíveis cópias de trechos do texto- } \\
\text { fonte, mas pouco significativa. }\end{array}$ & 2,0 \\
\hline & & $\begin{array}{l}\text { Eventos principais presentes. Ausência de erros de compreensão e de } \\
\text { trechos distintos. }\end{array}$ & 3,0 \\
\hline \multirow{12}{*}{$\begin{array}{l}\mathbf{C} \\
\mathbf{O} \\
\mathbf{N} \\
\mathbf{S} \\
\mathbf{T} \\
\mathbf{R} \\
\mathbf{U} \\
\mathbf{C} \\
\mathbf{A} \\
\mathbf{O}\end{array}$} & \multirow{3}{*}{$\begin{array}{l}\text { Autonomia } \\
\qquad 2 \mathrm{p}\end{array}$} & $\begin{array}{l}\text { Ausente - cópia total ou predominante do texto-fonte. } \\
\text { Resumo com história distinta do texto-fonte. Erros de compreensão. } \\
\text { Resumo insuficiente. }\end{array}$ & 0 \\
\hline & & Cópia parcial. Trechos distintos do texto-fonte. Erros de compreensão. & 1,0 \\
\hline & & $\begin{array}{l}\text { Predomínio das próprias palavras. Possíveis erros de compreensão, mas } \\
\text { pouco significativos. }\end{array}$ & 2,0 \\
\hline & \multirow{9}{*}{$\begin{array}{l}\text { Estrutura } \\
\text { narrativa }\end{array}$} & $\begin{array}{l}\text { Estado inicial - cópia do texto-fonte. } \\
\text { Estado inicial ausente ou insuficiente. Texto distinto do original. Erros de } \\
\text { compreensão. }\end{array}$ & 0,0 \\
\hline & & $\begin{array}{l}\text { Estado inicial pouco definido ou delimitado. Possível presença de trechos } \\
\text { distintos. Possível presença de erros de compreensão e cópia de trechos do } \\
\text { texto-fonte. }\end{array}$ & 0,5 \\
\hline & & $\begin{array}{l}\text { Estado inicial definido/relativamente definido. Ausência de trechos distintos } \\
\text { ou de erros de compreensão. }\end{array}$ & 1,0 \\
\hline & & $\begin{array}{l}\text { Transformações - cópia do texto-fonte. } \\
\text { Transformações ausentes ou insuficientes. Erros de compreensão. Possível } \\
\text { presença de trechos distintos do original. }\end{array}$ & 0,0 \\
\hline & & $\begin{array}{l}\text { Transformações presentes, mas pouco definidas. Possíveis erros de } \\
\text { compreensão e possível presença de trechos distintos. Possível cópia. }\end{array}$ & 0,5 \\
\hline & & $\begin{array}{l}\text { Transformações presentes, com clareza/predominante clareza. Ausência de } \\
\text { trechos distintos ou de erros de compreensão. }\end{array}$ & 1,0 \\
\hline & & $\begin{array}{l}\text { Estado final - cópia do texto-fonte. } \\
\text { Estado final ausente ou insuficiente. Trechos distintos do texto-fonte. Erros } \\
\text { de compreensão. }\end{array}$ & 0,0 \\
\hline & & $\begin{array}{l}\text { Estado final pouco definido ou delimitado. Possíveis erros de compreensão } \\
\text { e possível presença de trechos distintos e cópia de trechos. }\end{array}$ & 0,5 \\
\hline & & $\begin{array}{l}\text { Estado final definido/em grande parte definido. Ausência de trechos distintos } \\
\text { ou de erros de compreensão. }\end{array}$ & 1,0 \\
\hline
\end{tabular}




\section{Conclusões}

Foi possível tecer algumas conclusões analisando-se os resultados das correlações entre os testes. A maior delas, entre a Consciência Metatextual e a Compreensão Leitora $(r=0,48)$, nos sugere que os sujeitos com um bom nível de compreensão leitora tendem a possuir uma consciência sobre textos também interessante. A relação entre esses aspectos também foi investigada por alguns autores, apesar de não haver muitos trabalhos nesse sentido. Entre eles, Cain e Oakhill $(1996)^{2}$, que trataram da representação mental de uma narrativa na avaliação da compreensão leitora. Os sujeitos com melhor desempenho em compreensão também tiveram um bom desempenho em testes que envolviam estrutura textual, pois logravam formar uma representação mental integrando os eventos de uma história, de acordo com os conhecimentos que eles tinham sobre narrativas. Como mencionam Spinillo, Mota e Corrêa (2010), a explicação para essa relação seria "porque ambas as habilidades se apoiam em uma representação mental global do texto" (p. 9). Isso nos levaria a acreditar que esse ponto em comum se limitaria a essa explicação, inclusive porque cada uma dessas habilidades (compreensão e consciência) tem focos distintos. Porém, como as autoras acrescentam, pesquisas que tratam de conteúdo, compreensão e de macroestrutura tratam, de forma indireta, da consciência metatextual. Esta pode ser abrangente, tratando do texto em si como dos processos de leitura.

O que se pode sugerir, pelos dados gerados na pesquisa da tese tratada aqui, é que a consciência metatextual permeia atividades relacionadas diretamente à busca de compreensão de um texto, qualquer gênero ou tipo que seja ele. A compreensão leitora, talvez, seja em parte alimentada pela consciência sobre textos, isso dependendo do tipo e do gênero textual com que se trabalha. Estes podem determinar melhor ou pior desempenho na atividade de compreensão - não é arbitrária a escolha pelo

\footnotetext{
2 CAIN, K.; OAKHILL, J. The nature of the relationship between comprehension skill and the ability to tell a story. British Journal of Developmental Psychology, n. 14, p. 187-201, 1996. Nesse trabalho, os autores analisaram a habilidade metatextual em
}

professor por textos narrativos, informativos, argumentativos, pois ela depende do grau de complexidade compatível com a maturidade dos alunos.

Quanto à correlação entre Consciência Metatextual e Resumo $(r=0,44)$, igualmente considerada moderada, o que concluímos é que, como esta consciência de certo modo orienta a leitura e compreensão de textos, também pode exercer essa função junto à tarefa de reescrita de textos, em especial, resumo de narrativas - amplamente marcadas por caracterizações de personagens, situação inicial e final e transformações. A tendência pode ser a de o sujeito reescrever uma história à luz do próprio modelo superestrutural da história, guiandose pela sua forma e seu conteúdo, relacionado à macroestrutura. Além do impacto da presença de personagens e enredo, que podem criar certa curiosidade no leitor, pesquisa de Teberoski $(1995)^{3}$ pode reforçar nossa suposição de que a criança procura reproduzir o modelo do que leu. Conforme as conclusões de um estudo dessa autora, os sujeitos lograram manter as características do texto-fonte relacionadas à fidelidade ao assunto, à sintaxe e ao gênero do texto que foi apresentado. Essa reprodução das características deu-se tanto no nível de conteúdo como no nível de forma. Os sujeitos, ao elaborarem um resumo de história, podem ser mais influenciados pela sua consciência metatextual. Eles tomam o textofonte como um guia para sua produção escrita, e o reelaboram tendo em vista a forma como ele se apresenta, em termos de superestrutura (início, desenvolvimento, final). Embora as produções escritas sejam deficientes de modo geral, pois a escrita é, reconhecidamente, uma atividade complexa, elas foram amparadas por um texto original, e foram ao encontro do que pretendíamos: analisar superestrutura, autonomia e eventos principais, dispostos em uma macroestrutura advinda do texto original. O Resumo representa a macroestrutura da

crianças previamente definidas com níveis de compreensão distintos: mediano, bom e abaixo do esperado.

3 TEBEROSKY, A. (1995). Compor textos. Em A. Teberosky \& L. Tolchinsky (Orgs.) Além da alfabetização (pp. 85-116). São Paulo: Ática. 
narrativa, conferida pela coerência global; e a Consciência Metatextual teria relação estreita com a Superestrutura. Assim, o sujeito tem seu desempenho coerente em se tratando dessas variáveis. O mesmo não se pode dizer da correlação do Resumo com o teste de Compreensão Leitora.

A correlação menos significativa, ou fraca segundo parâmetros de Cohen (1988), foi entre a Compreensão Leitora e o Resumo. Em dissertação desta autora, em que se comparavam desempenhos entre resumo de texto informativo e teste de compreensão leitora de escolha simples, não se observou uma correlação importante. O mesmo ocorreu comparando-se esses dois testes na pesquisa da tese que tratamos aqui. À semelhança do que se concluiu naquele trabalho de final de curso, percebese que, como testes de escolha simples têm caráter pontual em suas questões, eles avaliam habilidades distintas dos sujeitos, têm um formato padrão e têm respostas mais previsíveis, de certa forma. O teste de compreensão leitora, nos moldes em que foi concebido - com questões de escolha simples - não ofereceu subsídios para a escrita de um resumo, talvez por tratar do texto-fonte de forma compartimentada, sem ênfase nos eventos da história. Já o resumo de narrativa é uma reprodução, e cabe aqui citarmos Brandão e Spinillo (1998):

Ao reproduzir, a criança precisa ter em mente dois níveis de texto: aquele que serve de modelo e aquele que está a produzir. Portanto, a reprodução requer atenção a um modelo apresentado. Além disso, ao reproduzir é preciso, em certo sentido, selecionar os aspectos do texto original que são relevantes a serem reproduzidos, bem como as relações essenciais entre esses aspectos. (p.15, grifo desta autora)

Acrescentamos que, já que se trata de modelo, trata-se essencialmente de um formato típico - neste nosso caso, narrativo, e que remete à superestrutura, correlacionada com a produção de resumos. As autoras concluem que há aspectos gerais comuns a qualquer ato de compreender, e que esse fato não exclui a existência de aspectos específicos de determinados testes - como na tese tratada aqui, de escolha simples para a Compreensão Leitora.
Acreditamos que o fato de essa correlação CL e R ser fraca reforça uma proposta de atividades que possam avaliar habilidades diferentes nos sujeitos, e que sejam vistas como complementares. "Assim, um único instrumento não revela todos os aspectos envolvidos na compreensão, e tarefas distintas podem requerer diferentes mecanismos cognitivos e linguísticos" (idem, p. 15). Além disso, Charolles (1991) afirma que o resumo é um teste que avalia as capacidades de compreensão e produção escrita. Sendo também utilizado como uma evidência de compreensão, pode ser colocado lado a lado a outro tipo de teste que trata o texto original de forma mais segmentada, como o teste de escolha simples que utilizamos nos testes aplicados aos sujeitos.

A tese que originou este artigo apresentou uma perspectiva psicolinguística em que se aliaram análise de texto - sua estrutura, coesão e coerência - e compreensão leitora. Nossa hipótese geral, de que havia correlação entre a Consciência Metatextual, a Compreensão Leitora e a produção de Resumo de narrativa por alunos de $5^{\circ}$ e $6^{\circ}$ anos do ensino fundamental, foi testada e confirmada. O que se sobressaiu desta investigação foi a medida em que houve essa correlação, o que foi verificado através dos objetivos específicos, advindos das hipóteses específicas. Devido ao espaço de que dispomos para este artigo, cabe apenas acrescentar que a tese também contou com a comparação dessas três variáveis entre as escolas que participaram do estudo, e os resultados podem ser vistos no trabalho original, que se encontra disponível para acesso via internet. A tese apresentou, em suma, a Consciência Metatextual como ponto em comum entre a Compreensão Leitora e a produção de Resumo de narrativa por sujeitos de $5^{\circ}$ e $6^{\circ}$ anos do ensino fundamental. Constatou-se que, para um sujeito resumir uma história, a competência que deverá estar mais presente é sua habilidade metatextual, ou seja, sua atenção para a superestrutura do texto-fonte. Essa consciência metatextual também pode ser importante para se verificar sua compreensão do texto através de teste de escolha simples, na medida em que se constitui numa espécie de moldura que 0 orienta a tentar 
compreender uma história. Apesar de nossa intenção ter sido avaliar a leitura através de três instrumentos diferentes, um deles, a Consciência Metatextual, se colocou como vértice que se relaciona à escrita de resumo e ao teste objetivo de compreensão leitora.

Como ocorre com todas as investigações, o objetivo geral diz respeito às suas contribuições para uma determinada área de conhecimento. Os dados empíricos foram gerados a partir de uma metodologia que utilizou instrumentos criados para um tipo de contexto e de amostra, e acreditamos que a contribuição metodológica mais relevante desta pesquisa é o instrumento do Quadro 5, que foi referência para se avaliarem os resumos dos sujeitos. Tal Quadro foi elaborado a partir das produções escritas, e foi sendo revisado exaustivamente ao longo das correções até chegarmos a um quadro aplicável a todas as produções. Isso evidencia que protocolos prontos de testagem, que se deseja aplicar indistintamente, nem sempre logram evidenciar uma determinada realidade de indivíduos e contextos sociais, pois se perde a especificidade de uma investigação. Pode-se dizer que a potencialidade dessa pesquisa deve-se a esse caráter ad hoc de averiguação, quando se dá enfoque a uma situação e se constroem instrumentos para avaliação específica dessa realidade. Esse trabalho de conclusão pode ser uma fonte de inspiração para outras investigações que considerem a realidade dos sujeitos, e que criem de modo quase personalizado instrumentos de avaliação de desempenho de grupos dos sujeitos.

Importante também apresentar aqui as possíveis fragilidades encontradas nos resultados da pesquisa. Entre elas está a interposição análise e conteúdo na avaliação das produções, ao mesmo tempo podendo ser vista como uma contribuição, pois induz a novas reflexões. As diferenças nos escores deveram-se, apesar de se tratar de ambientes públicos de ensino, a realidades diferenciadas, tanto em termos de alunos como de professores e suas formações e contextos de trabalho. Apesar disso, essas especificidades apontaram para algo em comum, que foi o papel importante da consciência metatextual, como explanado anteriormente: as escolas se distinguem, porém se unem pelos resultados, que indicam a consciência metatextual como relevante para a compreensão leitora e para a produção de resumo de histórias. Já a análise dos escores dos resumos, que se correlacionaram de modo fraco com os do teste de compreensão leitora, sugere que possa ter havido uma interferência entre a avaliação da expressão e a avaliação do conteúdo propriamente dito das produções, aspectos contemplados em conjunto no Quadro 5. Isso faz emergirem questões interessantes: até que ponto a avaliação do Resumo se constituiu como avaliação da compreensão leitora, através do conteúdo em si das produções; e se essa avaliação não sofreu interferência da construção do resumo, averiguada através do quadro-instrumento de referência para sua análise, onde se delimitaram as categorias dessas produções escritas e onde, também, estavam presentes aspectos do conteúdo do texto-fonte nas produções. Esses pontos serão explorados em estudos posteriores, de modo a se discutir mais estritamente os resultados da avaliação da compreensão através de produções escritas, ou seja: a compreensão tanto por meio do conteúdo como por meio da expressão formal - seus limites e intersecções.

Tendo por referência Spinillo (2009), nosso objetivo central, ou seja, verificar correlações entre Resumo, Consciência Metatextual e Compreensão Leitora, acabou por revelar algumas particularidades de diferentes tipos de avaliação - considerando-se habilidades muito próprias dos alunos, e que podem ser exploradas de modo mais sistemático pelos professores. Somando-se a isso, lançamos mão de uma metodologia que partiu de uma estrutura fixa Consciência Metatextual composta de coerência, coesão e estrutura textual - presente em um teste de dez questões que contemplaram esses aspectos, e acrescentou uma avaliação escrita: o resumo de uma narrativa. O grande desafio de se avaliar essas produções dos sujeitos foi considerar o que esse material escrito nos fornecia gradualmente, na leitura de cada um. As diretrizes para avaliação dos resumos também se inspiraram em trabalho de pesquisadora na área, porém, seguiram um caminho próprio devido 
justamente a esse caráter contingente dos resumos. Em outros trabalhos nessa linha, acreditamos que podem ser utilizados os critérios que consideramos na avaliação das produções deste trabalho, visto que não se tem conhecimento de uma avaliação de resumo de narrativa com esses parâmetros. Obviamente, estes não têm caráter prescritivo, e sim podem complementar outras pesquisas sobre o assunto.

\section{Referências}

ALVES, Sandra Maria Leal. Estratégias de compreensão leitora e de produção de resumo do gênero científico: aspectos textuais e cognitivos. Tese (doutorado em Letras). Pontifícia Universidade Católica do Rio Grande do Sul, Porto Alegre, 2010.

BRANDÃO, Ana Carolina P.; SPINILLO, Alina G. Aspectos gerais e específicos na compreensão de textos. Psicol. Reflex. Crit. [online], 1998, vol 11, n.2, p.p. 253-272.

CHAROLLES, Michael. Marquages linguistiques et resumé de texte. In: CHAROLLES, Michel; PETITJEAN, André. Le resumé de texte. Actes du Colloque International de Linguistique. Paris: Klincksieck, 1991.

COLOMER, Teresa; CAMPS, Anna. Ensinar a ler, ensinar a compreender. Tradução: Fátima Murad. Porto Alegre: Artmed, 2002.

GOMBERT, Jéan-Émile. Metalinguistic development. Hertfordshire: Harverster Wheatsheaf, 1992.

GOMBERT, Jéan-Émile. Atividades metalinguísticas e aprendizagem da leitura. In: MALUF, Maria Regina (org.) Metalinguagem e aquisição da escrita: contribuições da pesquisa para a prática da alfabetização. São Paulo: Casa do Psicólogo, 2003. p. 19-63.

Epi/meta versus implícito/explícito: nível de controle cognitivo sobre a leitura e sua aprendizagem. In: MALUF, Maria Regina; CARDOSO-MARTINS, Cláudia (orgs.). Alfabetização no século XXI - como se aprende a ler e a escrever. Porto Alegre: Penso: 2013.

KATO, Mary A. O aprendizado da leitura. São Paulo: Martins Fontes, 1999.

LEFFA, Vilson. Aspectos da Leitura - uma perspectiva psicolinguística. Coleção Ensaios. Porto Alegre: Sagra-Luzzatto, 1996.

RODARI, Gianni. Histórias para brincar. São Paulo, Editora 34, 2007.

SOLË, Isabel. Estratégias de leitura. Porto Alegre: Artes Médicas, 1998. 194p.

SPINILLO, Alina G.; MOTA, Márcia Maria P.E. da; CORRÊA, Jane. Consciência metalinguística e compreensão em leitura: diferentes facetas de uma relação complexa. Educar em Revista, Curitiba, Brasil, n. 38, p. 157-171, set./dez. 2010. Editora UFPR.

SPINILLO, Alina G. A consciência metatextual. In: MOTA, Márcia da (org.). Desenvolvimento metalinguístico: questões contemporâneas. São Paulo: Casa do Psicólogo, 2009.

SPINILLO, Alina G.; SIMÕES, Patrícia U. O desenvolvimento da consciência metatextual em crianças: questões conceituais, metodológicas e resultados de pesquisa. Psicologia. Reflexão e Critica. 2003 16(3) pp. 537-546.

STERNBERG, Robert. Psicologia cognitiva. Tradução da 4⿳亠丷a edição norte-americana. São Paulo: Cencage Learning, 2010. 5 ed.

TUNMER, William E.; HERRIMAN, M. L. (1984). The development of metalinguistic awareness: a conceptual overview. Em W. E. Tunmer, C. Pratt \& M. L. Herriman (Orgs.), Metalinguistic awareness in children: theory, research and implications(pp. 1235). New York: Springer-Verlag.

VAN DIJK, Teun A.; KINTSCH, Walter.Strategies of discourse comprehension. New York: Academic Press, 1983.

\section{COMO CITAR ESSE ARTIGO}

LOPES, Marília Marques. Consciência metatextual, compreensão leitora e resumo de histórias - possíveis relações em uma perspectiva psicolinguística. Signo, Santa Cruz do Sul, v. 41, n. 71, set. 2016. ISSN $1982-2014$. Disponível em: <https://online.unisc.br/seer/index.php/signo/article/view/7195>. Acesso em: http://dx.doi.org/10.17058/signo.v41i71.7195. doi: 